(C) Copyright 2020: Editum. Servicio de Publicaciones de la Universidad de Murcia. Murcia (Spain) ISSN print edition: 0212-9728. ISSN online edition (http://revistas um es/analesps): 1695-2294.

Online edition License Creative Commons 4.0: BY-SA

\title{
Moderating Effects of Hardiness and optimism on negative life events and coping self- efficacy in first-year undergraduate students
}

\author{
Mohammad Abbasi*, Ezatollah Ghadampour, Mohammad Hojati, and Abas Senobar
}

Faculty of Literature and Humanities, Lorestan University, Khorramabad (Iran)

Título: Efectos moderadores de la resistencia y el optimismo sobre los eventos negativos de la vida y la autoeficacia de afrontamiento en estudiantes de primer año de pregrado.

Resumen: Introducción: Este estudio analiza el papel de la resistencia y el optimismo en los eventos negativos de la vida y la autoeficacia de afrontamiento en 228 estudiantes universitarios de primer año de la Universidad de Lorestan (Irán). El objetivo del estudio era doble: (1) analizar las asociaciones entre resistencia, optimismo, eventos de vida negativos y autoeficacia de afrontamiento; y (2) determinar si la resistencia y el optimismo moderan la relación entre los eventos negativos de la vida y la autoeficacia de afrontamiento.

Método: Este estudio correlacional descriptivo se realizó en el año escolar 2016-17. En este estudio, al principio seleccionamos 228 estudiantes. Luego, los estudiantes completaron el Cuestionario de Eventos de la Vida Adolescente (ALEQ), la Prueba de Orientación de la Vida revisada (LOTR), la Escala de Resistencia de Kobasa y la Escala de Autoeficacia (CSE) Se utilizaron análisis jerárquicos de regresión lineal para examinar el papel moderador de la resistencia y el optimismo.

Resultados: Los resultados revelan que existe una relación significativa entre resistencia, optimismo, eventos vitales negativos y autoeficacia de afrontamiento. La resistencia y el optimismo también fueron moderadores en la relación entre los eventos negativos de la vida y la autoeficacia de afrontamiento.

Conclusión: Los hallazgos respaldaron la hipótesis de que niveles más altos de resistencia y optimismo se asociarían con niveles más altos de autoeficacia de afrontamiento, y que niveles más bajos de resistencia y optimismo se asociarían con niveles más bajos de autoeficacia de afrontamiento. Finalmente, nuestros resultados implican que la resistencia y el optimismo son un moderador importante de los eventos negativos de la vida del estudiante sobre la autoeficacia de afrontamiento.

Palabras clave: Eventos negativos de la vida; Resistencia; Optimismo; Autoeficacia de afrontamiento; Estudiantes universitarios de primer año; Irán.

\section{Introduction}

First-year for the undergraduate students is not only a time for increased stress, but a time of increased risk for the development of physical, social, academic and psychological health problems due to the toll this stress can take. Stecker (2004) found that an alarming number of students reported symptoms of depression, stress, substance use, and even suicidal ideation. Research findings have indicated that pressure of work, especially preparing for examinations and acquiring professional knowledge, are the most stressful aspects (Karagiannopoulou \& Kamtsios, 2011). Other studies demonstrate that the most common stressors for undergraduates are fear of failure (Gibbons, 2015), stressors related to examinations

* Correspondence address [Dirección para correspondencia]: Mohammad Abbasi: Faculty of Literature and Humanities, Lorestan University, Khorramabad, Iran; abasi.mo@lu.ac.ir

(Article received: 05-11-2019; revised: 03-03-2020; accepted: 28-03-2020)
Abstract: Introduction. This study analyzes the role of Hardiness and optimism on negative life events and coping self-efficacy in 228 first-year undergraduate students from Lorestan University (Iran). The aim of the study was two-fold: (1) to analyze the associations between Hardiness, optimism, negative life events and coping self-efficacy; and (2) to determine whether Hardiness and optimism moderates the relationship between negative life events and coping self-efficacy.

Method: This descriptive correlational study was conducted in the school year of 2016-17. In this study, at first we selected 228 students. Then the students completed the Adolescent Life Events Questionnaire (ALEQ), Revised Life Orientation Test (LOT-R), Kobasa's Hardiness Scale, and Coping Self-Efficacy Scale (CSE). Hierarchical linear regression analyses were used to examine the moderating role of Hardiness and optimism. Results: Results reveal that there is a significant Relationship between Hardiness, optimism, negative life events and coping self-efficacy. Hardiness and optimism was also a moderator in the relationship between negative life events and coping self-efficacy.

Conclusion: The findings supported the hypothesis that higher levels of Hardiness and optimism would be associated with higher levels of Coping Self-Efficacy, and that lower levels of Hardiness and optimism would be associated with lower levels of Coping Self-Efficacy. Finally, our results imply that Hardiness and optimism is an important moderator of student's negative life events on Coping Self-Efficacy.

Keywords: Negative life events; Hardiness; Optimism; Coping SelfEfficacy; First-year undergraduate students; Iran. and time management (Robotham, 2008), feeling overwhelmed by workload (Reisberg, 2000).

Some students adapt successfully to stressful situations. One factor that has been shown to influence the response to Negative events is coping self-efficacy. Lazarus and Folkman (1984) define coping as cognitive or behavioral efforts put forth by individuals in an attempt to manage stressors (Pisanti, Lombardo, Lucidi, Lazzari \& Bertini, 2008). Coping selfefficacy (CSE) refer to an individual's beliefs about one's ability to cope with external stressors. Research in positive psychology has demonstrated that coping self-efficacy plays a significant role in predicting whether an individual will successfully or unsuccessfully adapt to stressful situations. A wide spectrum of empirical evidence documents the adaptive value of coping self-efficacy in promoting psychological wellbeing and successful adaptation to stress. High CSE has been related to a wide range of physiological measures including lower catecholamine responsivity during stress (Bandura, Taylor, Williams, Mefford, \& Barchas, 1985), pre- 
competitive anxiety and subjective performance among athletes (Nicholls, Polman, \& Levy, 2010), and better psychological adjustment to highly stressful life changes and events, such as aging (Kraaij, Garnefski, \& Maes, 2002, Benka, Nagyova \& Rosenberger, 2014). Thus, coping self-efficacy, or beliefs about an individual's ability to perform certain coping behaviors, influences outcomes of both learning and employing coping skills (Chesney, Neilands, Chambers, Taylor \& Folkman, 2006). Overall, these results suggest that CSE has direct effects on distress/well-being outcomes, beyond the impact of external stressors. A high level of coping self-efficacy tends to create an adaptive approach leading individuals to view tasks or situations that require high efforts as challenging and as positive experiences. Whereas, when CSE perceptions are low, it is more likely that individuals perceive the same tasks or situations as stressful and greater energy is directed to manage the increasing emotional distress (Pisanti, 2012, Bandura, 1997).

On the other hand, Individuals with sufficient psychological hardiness manage problem solving efficiently (Dubow $\&$ Luster, 1990). In turn, the adequate solution of problems can bolster self - efficacy (Bandura, 1986). Kobasa (1979) explained that the three personality attitudes of challenge, commitment, and control combined to produce psychological hardiness, which then assisted individuals to meet challenges within their environments and alter stressful life situations into occasions for personal development and enrichment. A paucity of challenge, commitment, and control personality dimensions often resulted in burnout (Kobasa, 1979). Researchers identified that psychological hardiness was the central 1 principle of resilience, which allowed individuals to cope and flourish when faced with stressful circumstances (Maddi \& Khoshaba, 1994). Hardiness has also been shown to be associated with the individual's use of active, problem focused coping strategies for dealing with stressful events (Gentry and Kobasa, 1984, Kobasa, 1982), enhanced self-esteem (Gito, Ihara, \& Ogata, 2012) and boost courage, competence, and humor (Kobasa, 1979). Furthermore, Creed, Conlon, and Dhaliwal (2013), found that hardy students are committed to their academic work, able to have control over their academic performance and outcomes and be willing to treat each task as a challenge and opportunity for learning.

Like Hardiness, optimism is an important variable in the life stress/psychological and physical health equation. Optimists are people who expect that good things will happen to them, while pessimists expect bad things to happen (Scheier \& Carver, 1985). As a positive personality trait, optimism refers to a tendency toward positive expectations for the future and confidence in one's ability to cope with challenges (Friedman \& Kern, 2014). Thus, people who have an optimistic orientation towards life tend do have positive expectations regarding the future, to realize that the desired is possible and to persist in their efforts (Scheier \& Carver, 1985). Prior research has documented the important role of optimism for people's psychosocial adaptation and well-being (Alarcon,
Bowling, \& Khazon, 2013; Krok, 2015). In a recent metaanalysis of optimism and its role as a stress-reducing resource, a large body of evidence concludes that optimism is positively correlated with life satisfaction, happiness, and psychological and physical well-being and negatively associated with depression and anxiety (Alacorn, Bowling \& Khazon, 2013). A different study, done by Aspinwall and Taylor (1992), showed that Optimism is associated to higher academic performance. Likewise, Optimism is associated to better professional performance (Long, 1993).

In short, Whereas many studies have regarded hardiness and optimism as an antecedent factor or as playing a mediation role for coping self-efficacy, relatively less is known with regard to hardiness and optimism as a moderator, the purpose of the present study was to examine hardiness and optimism predicted Coping self-efficacy, while controlling for the effects negative life events (Figure 1).

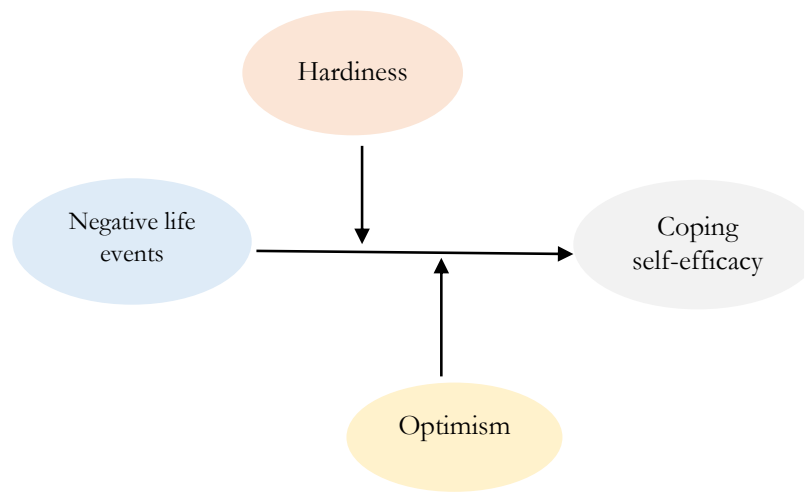

Figure 1. Moderating influence of Hardiness and optimism on the relationship between the negative life events and coping self-efficacy of firstyear undergraduate students.

\section{Aims of the study}

The aim of this study was to investigate whether Hardiness and optimism moderates the relationship between negative life events and coping self-efficacy in first-year undergraduate students. In order to address the aim, the following research questions were posed:

- Is there a significant relationship between negative life events and coping self-efficacy in first-year undergraduate students?

- Does Hardiness and optimism moderate the relationship between negative life events and coping self-efficacy in first-year undergraduate students?

\section{Method}

\section{Participants}

We sampled 228 first-year undergraduate students in lorrestan university, Iran. Students were aged 17 to 18 years. 


\section{Measures}

Revised Life Orientation Test (LOT-R): A 10 item scale developed by Scheier, Carver, and Bridges (1994) was used to measure Optimism levels of the participants. This measures dispositional Optimism. LOT-R includes 10 items: three statements about optimism (items 1, 4 and 10), three on pessimism (items 3, 7 and 9) and four distractor items (2, 5, 6, 8). Respondents indicate their degree of agreement with statements such as, "In uncertain times, I usually expect the best," using a five-point response scale ranging from "strongly disagree" to "strongly agree". It has been used extensively in studies of stress, both with college students and with people going through stressful events, such as medical populations facing or recovering from serious diseases or treatments. In this study, LOT-R was carefully translated and corresponded to the main scale by the authors. Then, to examine its validity, confirmatory factor analysis was carried out on its items and its reliability was calculated. Results indicate that the scale has appropriate psychometric qualities to be used in Iran. LOT-R internal consistency reliability using Cronbach's alpha was 0.76 .

Hardiness: Twenty item abridged Hardiness Scale developed by Kobasa, (1982) was used to measure Hardiness. All the items are rated on a four-point scale $(0=$ not at all true; $3=$ very true). The scale consist $\mathrm{s}$ of three dimensions: commitment (one of the examples of an item is "By working hard, you can always achieve your goal"), control (one of the examples of an item is "Most days, life is really interesting and exciting for me".) and challenge (one of the examples of an item is "My mistakes are usually difficult to correct"). Total score on this sale is considered for the assessment of Hardiness. The higher score on this scale indicates the higher the Hardiness. In this study, Hardiness Scale was carefully translated and corresponded to the main scale by the authors. Then, to examine its validity, confirmatory factor analysis was carried out on its items and its reliability was calculated. Results indicate that the scale has appropriate psychometric qualities to be used in Iran. Hardiness Scale internal consistency reliability using Cronbach's alpha was 0.76 .

Coping self-efficacy scale. The Coping Self-Efficacy Scale (CSE; Chesney et al., 2006) is a 26-item measure assessing individuals' confidence in performing coping behaviors when confronted with challenges. Participants are asked to respond to the question, "When things aren't going well for you, or when you're having problems, how confident or certain are you that you can do the following:" A 10-point scale is used to rate the extent to which participants believe they can perform different adaptive coping behaviors. Scale anchor points are 1 ('cannot do at all'), 5 ('moderately certain can do'), and 10 ('certain can do'). An overall CSE score is created by summing item ratings $(\alpha=.95 ; M=137.4, S D=$ 45.6) (Chesney et al., 2006). Three factors contribute to the CSE scale; problem focused coping $(\alpha=.91)$, stopping unpleasant thoughts or emotions $(\alpha=.91)$, and social support $(\alpha=.91)$ (Chesney et al., 2006). Internal consistency and test- retest reliability ( $\mathrm{r}=.4$ to .8 ) are high for all three factors (Chesney et al., 2006). Concurrent validity analyses demonstrate that these factors assess self-efficacy for different types of coping. Predictive validity analyses showed that using problem- and emotion focused coping skills was predictive of reduced psychological distress and increased psychological well-being over time (Chesney et al., 2006). In this study, coping self-efficacy scale was carefully translated and corresponded to the main scale by the authors. Then, to examine its validity, confirmatory factor analysis was carried out on its items and its reliability was calculated. Results indicate that the scale has appropriate psychometric qualities to be used in Iran. PSS internal consistency reliability using Cronbach's alpha was 0.84 .

Adolescent Life Events Questionnaire. The Adolescent Life Events Questionnaire (ALEQ; Hankin \& Abramson, 2002) is a 70 item self-report check list that assesses a broad range of negative life events typically occurring among adolescents (approximate ages 13-18). The negative events are classified into four domains relevant to adolescents: 1) $\mathrm{Fa}$ mily and parents (e.g., You and your family moved to a new town, but you did not want to movell), 2) romantic relationships (e.g., Got in a fight/argument with a boyfriend/girlfriendll), 3) school and classes (e.g., Did poorly on, or failed, a test or class projectll), and 4) friends and social activities (e.g., Don't have as many y friends as you would like to). Adolescents are asked to read each event and indicate Yes\|l or Noll if the event happened to them in the last three months. Scores were calculated by counting the number of Yes items within each domain to obtain a total scale score. For the purposes of this study, the ALEQ was carefully translated and corresponded to the main scale by the authors. Then, the 69-item ALEQ was used to assess negative life events $(29$ items $=$ Family and parents, 11 items $=$ school and classes and 19 items = friends and social activities). The internal consistency $(a=.69)$ was acceptable for this study.

\section{Procedure}

Analysis of the data from this study was performed using SPSS 24.0 statistical software. Missing values in the data were computed along with the sample means. The moderator effects of Hardiness and optimism were tested using hierarchical multiple regression analysis based on the steps of Baron and Kenny's (1986) moderating model. In order to decrease the multicollinearity problems in the analyses, standard z-scores were used. Details about data analyses are given in the section on findings.

\section{Data analysis}

Descriptive and correlational analysis. Descriptive statistics and bivariate correlation for the negative life events, Hardiness and optimism and coping self-efficacy are presented in Table 1. As expected, Hardiness was positively correla- 
ted with coping self-efficacy $(r=0.64, p<.01)$, optimism $(r=$ $0.65, p<.01)$, and negatively correlated with negative life events $(r=-0.43, p<.01)$, also, optimism was negatively correlated with negative life events $(r=-0.47, p<.01)$ and po- sitively correlated with coping self-efficacy $(r=0.68, p<$ .01). In addition, skewness and kurtosis values were found to be within acceptable range for a normal distribution.

Table 1. Means, standard deviations, skewness, kortosis and correlations of the variables.

\begin{tabular}{|c|c|c|c|c|c|c|c|}
\hline Variable & Skewness & Kurtosis & $M$ & $S D$ & 1 & 2 & 3 \\
\hline 1. negative life events & .23 & -1.41 & 28.07 & 17.98 & & & \\
\hline 2. Hardiness & -.11 & -1.17 & 33.71 & 13.30 & $-.43 * *$ & & \\
\hline 3. optimism & -.38 & -1.10 & 25.88 & 9.24 & $-.47 * *$ & $.65^{* *}$ & \\
\hline 4. coping self-efficacy & .51 & -1.23 & 151.16 & 62.64 & $-.73 * *$ & $.64 * *$ & $.68 * *$ \\
\hline
\end{tabular}

** Correlation is significant at $p<.01$

\section{Results}

Moderating effects of Hardiness and optimism. In order to test the moderating effects of Hardiness and optimism on the relationship between negative life events and coping selfefficacy, hierarchical multiple regression procedures were conducted, as recommended by Baron and Kenny (1986). For each potential moderator variable, regression models were performed separately. In the first step, we entered gender as a covariate. In the second step, the predictor variable (negative life events) was entered into the regression equation. At step 3, potential moderator variables (Hardiness and optimism) were entered into the regression equations. In the final step, interaction variables (negative life events $\mathrm{x}$ Hardiness; negative life events x optimism) were entered into the models. Significant change in $\mathrm{R}^{2}$ for the interaction term indicates a significant moderator effect.

Table 2. Hierarchical Regression Model for Moderator Role of optimism in the Relationship between negative life events and coping self-efficacy in firstyear undergraduate students.

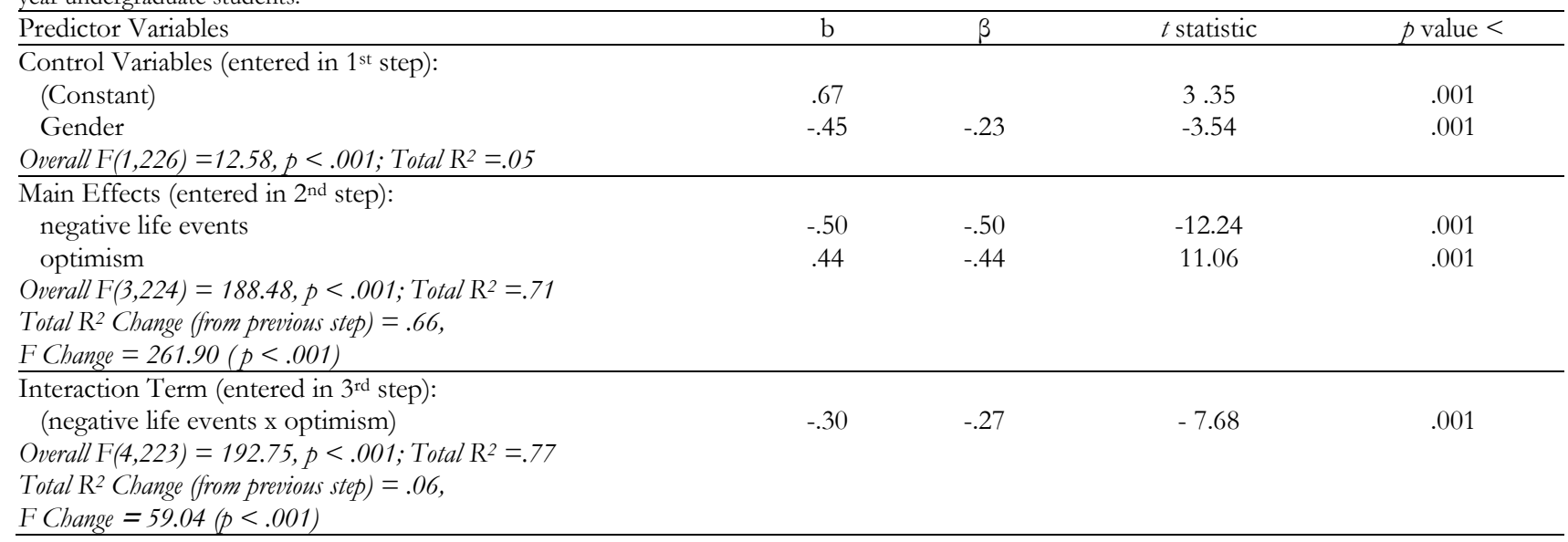

Of greatest importance was the significant interaction between negative life events and Hardiness $(p<.001)$ and optimism $(p<.001)$. To illustrate the nature of the interaction effect, we examined the relationship between negative life events and students coping self-efficacy at a high level of Hardiness and optimism (one standard deviation above the mean) and at a low level of Hardiness and optimism (one standard deviation below the mean; Aiken \& West, 1991). As can be seen in Figure 2 and Figure 3, when Hardiness and optimism was low (but not when Hardiness and optimism was high), higher levels of negative life events led to lower coping self-efficacy.

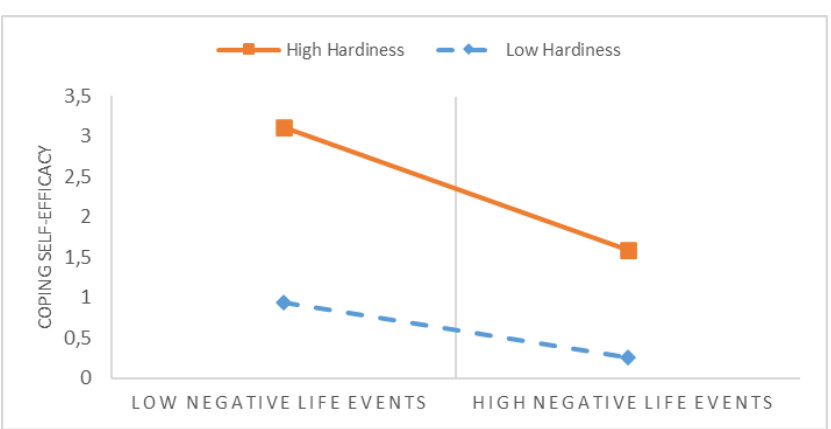

Figure 2. The Interactive Effect of negative life events and Hardiness on coping self-efficacy in first-year undergraduate students. 


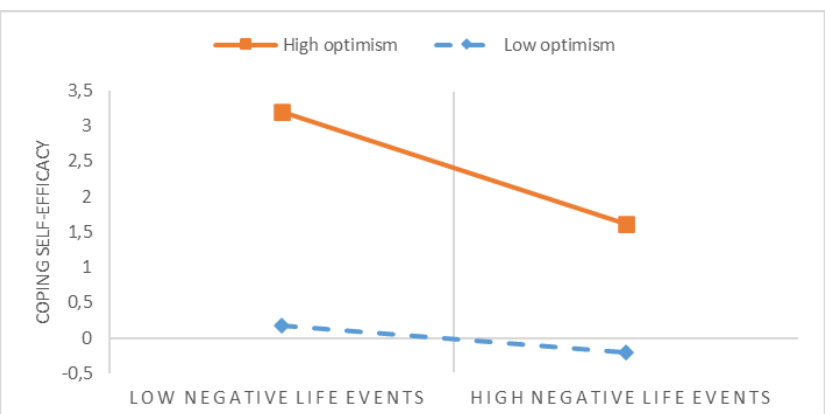

Figure 3. The Interactive Effect of negative life events and optimism on coping self-efficacy in first-year undergraduate students.

\section{Discussion and Conclusion}

The present study had two objectives. The first objective was an examination of the predictive value of negative life events and coping self-efficacy. The second, was to determine the ability of Hardiness and optimism to act as moderators on that relationship. Results at the individual level of analysis indicate that negative life events was negatively correlated with coping self-efficacy. The results of the study support other studies that found a negative relationship between negative life events and coping self-efficacy (Benka et al. 2014; Pisanti, 2012, Kraaij, Garnefski, \& Maes, 2002, Bandura, 1997). Further, in a study, Vaezi and Fallah (2011) found significant negative correlations $(p<.01)$ between stress and dimensions of self -efficacy. In another study, Betoret (2006) reported that teachers who felt high levels of stress were found to have low levels of self - efficacy. According to another important finding of the study Hardiness and optimism has a moderator role in the relationship between negative life events and coping self-efficacy. According to the results of the current study, less negative life events and more coping self-efficacy was observed in students with a high Hardiness and optimism compared to students with a low Hardiness and optimism. The results are consistent with the other studies presenting the relationship of Hardiness with coping self-efficacy (Maddi, 2002; 1994) and optimism with

\section{References}

Alarcon, G.M., Bowling, N.A., \& Khazon, S. (2013). Great expectations: A meta-analytic examination of optimism and hope. Personality and Indivi$\begin{array}{lll}\text { dual Differences, } & \text { 84, }\end{array}$ http://dx.doi.org/10.1016/j.paid.2012.12.004.

Aiken, L. S., \& West, S. G. (1991). Multiple regression: Testing and interpreting interactions. Newbury Park: Sage.

Alacorn, G. M., Bowling, N. A., \& Khazon, S. (2013). Great expectations: A meta-analytic examination of hope and optimism. Personality and Individual Differences, 54, 821-827.

Aspinwall, L. G. \& Taylor, S. E. (1992). Modeling cognitive adaptation: a longitudinal investigation of the impact of individual differences and coping on college adjustment and performance. Journal of Personality and Social Psychology, 61, 755-765.

Baron, R. M., Kenny D. A. (1986). The moderator-mediator variable distinction in social psychological research: conceptual, strategic, and sta- coping self-efficacy (Krok, 2015; Friedman \& Kern, 2014; Alarcon, Bowling, \& Khazon, 2013).

This findings has several plausible explanations. Psychological hardiness is a personality characteristic, attitude, and cognitive appraisal mechanism, which is teachable, reactive, and can be nurtured in early life. Studies identified that psychological hardiness helps individuals to moderate stress and confront challenges thereby encouraging health and wellness (Bartone, 2006; Kobasa, 1979). A second explanation for this finding is that the Hardy and optimistic adolescents use more of adaptive cognitive coping strategies, when coping with negative incidents.

In sum, In this study we have attempted to increase knowledge of the moderating role of personal characteristics (Hardiness and optimism) in the negative life events. Several limitations must be acknowledged in the present study. First, it is important to note that the present study was cross-sectional, meaning that results can only be interpreted as correlational and direction of causality cannot be determined. Future studies should be encouraged to overcome these limitations by longitudinal design, which would enable quantification regarding the effectiveness of intervention Hardiness and optimism in moderating the relationship between role negative life events and coping self-efficacy. Another issue related to measurement is that data in this study was obtained using self-report measures, and the results may be contaminated by the variance of the common method. It would be appropriate to complement these measurements with others obtained with different methods. Despite these limitations, the findings of the present study have numerous implications for theory and practice. Considering these findings, coping self-efficacy decreases as negative life events, and this decrease is higher for the students who have low Hardiness and optimism. These findings suggest that attention to program dynamics or culture could improve students' Hardiness and optimism. Thus, an implication of our results is that interventions focused on increase coping self-efficacy may need to increase Hardiness and optimism.

tistical considerations. Journal of Personality and Social Psychology, 51, 11731182. doi: 10.1037/0022-3514.51.6.1173.

Bandura, A. (1986). Social foundations of thought and action: A social cognitive theory. Englewood Cliffs, NJ: Prentice Hall.

Bandura, A. (1997). Social Foundations of Thought and Action: A Social Cognitive Theory. Freeman, New York, NY.

Bandura, A., Taylor, C., Williams, S., Mefford, I., \& Barchas, J. (1985). Catecholamine secretion as a function of perceived coping self-efficacy. Journal of Consulting and Clinical Psychology, 53, 406-414. doi: 10.1037/0022- 006X.53.3.406.

Bartone, P. T. (2006). Resilience under military operational stress: Can leaders influence hardiness. Military Psychology, 18 (S), S131 - S148.

Benka, J., Nagyova, I., Rosenberger, J. et al. (2014). Is Coping Self-Efficacy Related to Psychological Distress in Early and Established Rheumatoid Arthritis Patients? Journal of Developmental and Physical Disabilities, 26, 285. doi: 10.1007/s10882-013-9364-y. 
Betoret, F. D. (2006). Stressors, self - efficacy, and coping resources and burnout among secondary school teachers in Spain. Educational Psychology, 26 (4), 519 - 539. doi: 10. 1080/01443410500342492.

Chesney, M. A., Neilands, T. B., Chambers, D. B., Taylor, J. M., \& Folkman, S. (2006). A validity and reliability study of the Coping SelfEfficacy scale. British Journal of Health Psychology, 11(3), 421-437. doi: 10.1348/135910705X53155.

Creed, P., Conlon, E., \& Dhaliwal, K. (2013). Revisiting the academic hardiness scale: Revision and revalidation. Journal of Career Assessment, 21(4), 537-554. doi: 10.1177/1069072712475285.

Dubow, E. F., \& Luster, T. (1990). Adjustment of chil dren born to teenage mothers: The contribution of risk and protective factors. Journal of $\mathrm{Ma}$ rriage and the Family, 52(2), 393-404. doi: 10.2307/353034.

Friedman, H.S., \& Kern, M.L. (2014). Personality, well-being, and health. Annual Review of Psychology, 65, 719-742. http://dx.doi.org/10.1146/annurev-psych-010213-115123.

Gentry, W. D., \& Kobasa, S. C. (1984). Social and psychological resources mediating stress-illness relationships in humans. In W. D. Gentry (Ed.), Handbook of behavioral medicine, (87-116). New York: Guilford Press.

Gibbons, C. (2015). Stress, eustress and the national student survey. Psychology of Teaching Review, 21(2), 86-91.

Gito, M., Ihara, H., \& Ogata, H. (2012). The relationship of resilience, hardiness, depression, and burnout amo ng Japanese psychiatric hospital nurses. Journal of Nursing Education and Practice, 11 (3), 12 - 18. doi: $10.5430 /$ jnep.v3n11p12.

Hankin, B.L., \& Abramson, L.Y. (2002). Measuring cognitive vulnerability to depression in adolescence: Reliability, validity, and gender differences. Journal of Clinical Child \& Adolescent Psychology, 31, 491-504. doi: 10.1207/S15374424JCCP3104_8.

Karagiannopoulou, E., \& Kamtsios, S. (2011). Stages of change, selfefficacy and stress management perceptions in undergraduate students. International Journal of Psychology and Behavioral Sciences, 1(1), 1-9. doi: 10.5923/j.ijpbs.20110101.04.

Kraaij, V., Garnefski, N., \& Maes, S. (2002). The joint effects of stress, coping, and coping resources on depressive symptoms in the elderly. $A n$ xiety, Stress and Coping, 15, 163-177. doi: 10.1080/10615800290028468.

Kobasa, S. C. (1979). Stressful life events, personality, and health: An inquiry into hardiness. Journal of Personality and Social Psychology, 37(1), 1-11. doi: $10.1037 / 0022$ - 3514.37.1.1

Kobasa., S.C. (1982). Commitment and Coping in stress resistance among lawyers. Journal of Personality and Social Psychology, 42, 707-717.

Krok, D. (2015). The mediating role of optimism in the relations between sense of coherence, subjective and psychological well-being among late adolescents. Personality and Individual Differences, 85, 134-139. http://dx.doi.org/10.1016/i.paid.2015.05.006.

Lazarus, R. S., \& Folkman, S. (1984). Stress, appraisal, and coping. New York: Springer.

Long, B. C. (1993). Coping strategies of male managers: a prospective analysis of predictors of psychosomatic symptoms and job satisfaction. Journal of Vocational Behavior, 42, 184-199. doi: 10.1006/jvbe.1993.1013.

Maddi, S. R., \& Khoshaba, D. M. (1994). Hardiness and mental health. Journal of Personality Assessment, 63 (2), 265-274. doi: 10.1207/s15327752jpa6302_6.

Maddi, S. R. (2002). The story of hardiness: Twenty years of theorizing, research, and practice. Consulting Psychology Journal, 54(3), 173-185. doi: 10.1037/1061 - 4087.54.3.173

Nicholls, A. R., Polman, R., \& Levy, A. R. (2010). Coping self-efficacy, precompetitive anxiety, and subjective performance among athletes. European Journal of Sport Science, 10, 97-102. doi.org/10.1080/17461390903271592.

Pisanti, R. (2012). Coping self-efficacy and psychological distress: results from an Italian study on nurses. The European Health Psychologist, 14(1), $11-14$

Pisanti, R., Lombardo, C., Lucidi, F., Lazzari, D., \& Bertini, M. (2008). Development and validation of a brief Occupational Coping Self-Efficacy Questionnaire for Nurses. Journal of Advanced Nursing, 62(2), 238-247. doi:10.1111/j.1365-2648.2007.04582.x

Reisberg, L. (2000). Student stress is rising, especially among young women. The Chronicle of Higher Education, 46(21), 49-50.

Robotham, D. (2008). Stress among higher education students: Towards a research agenda. Higher Education, 56, 735-746. doi: 10.1007/s10734008-9137-1.

Scheier, M. F. \& Carver, C. S. (1985). Optimism, coping, and health: assessment and implications ofgeneralized outcome expectancies. Health Psychology, 4, 219-247.

Scheier, M. F. Carver, C. S., \& Bridges, M. W. (1994). Distinguishing optimism from neuroticism (and trait anxiety, self-mastery, and selfesteem): A re-evaluation of the Life Orientation Test. Journal of Personality and Social Psychology, 67, 1063-1078. doi: 10.1037//00223514.67.6.1063.

Stecker, T. (2004). Well-being in an academic environment. Medical Education, 38(5), 465-478.

Vaezi, S., \& Fallah, N. (2011). The relationship between self - efficacy and stress among Iranian EFL teachers. Journal of Language Teaching and Research, 2(5), 1168 - 1174. doi:10.4304/jltr.2.5.1168 - 1174. 